\title{
Analysis of Coagulation Factor Activity of Normal Adults with APTT Limit Range
}

\author{
Eui-Hoon Kwon ${ }^{1}$, Bon-Kyung Koo ${ }^{1}$, Sung-Hwan Bang ${ }^{1}$, Hee-Jin $\mathrm{Kim}^{2}$, and Young-Kuk Cho ${ }^{3}$ \\ ${ }^{1}$ Department of Laboratory Medicine, Samsung Medical Center, Seoul 06351, Korea \\ ${ }^{2}$ Department of Laboratory Medicine, Samsung Medical Center, Sungkyunkwan University School of Medicine, Seoul 06351, Korea \\ ${ }^{3}$ Department of Medical Laboratory Science, Seoyeong University, Seoul 06351, Korea
}

\section{APTT에서 경계치에 속한 정상 성인의 혈액응고인자 활성도 분석}

\author{
권의훈 ${ }^{1}$, 구본경 $^{1}$, 방성환 $^{1}$, 김희진 $^{2}$, 조영국 ${ }^{3}$ \\ ${ }^{1}$ 삼성서울병원 진단검사의학과, ${ }^{2}$ 성균관대학교 의과대학 삼성서울병원 진단검사의학과, ${ }^{3}$ 서영대학교 임상병리과
}

\begin{abstract}
The coagulation factor activity compared two groups of the lower 10\% (29.1 30.9 sec) and the upper $10 \%(38.0 \sim 41.9 \mathrm{sec})$ of the normal reference range of aPTT. The aim of this study was to investigate the influence of sex, age, and ABO blood type on coagulation factor activity. There was significant difference in the activity of the coagulation factor assay based on age. The VIII ( $p$ $<0.0001)$ and IX ( $p=0.0050)$ in the lower group of samples from those over sixty years of age is higher than from those under sixty. In contrast, XII ( $p=0.0285)$ for samples over sixty was lower than for samples under sixty. While in the upper group V $(p=0.0219)$, VIII $(p=0.0005)$, and IX $(p=0.0014)$ for samples from the over sixty group was higher than those under sixty. In the case of activity of coagulation factor between $\mathrm{O}$ and non-O blood type, VIII $(p<0.001)$ activity of the non-O blood type was higher than that of the O blood type in the both groups. The XII $(p=0.016)$ activity of non-O blood type was lower than that of O blood type in the upper group. According to the multiple logistic regression analysis, when other variables are under the same conditions between lower and upper groups, there is a strong possibility for the lower group when activity of $\mathrm{V}(p=0.001), \mathrm{VIII}(p<0.001), \mathrm{X}(p<0.001)$ and $\mathrm{XII}(p<0.001)$ is increased. Furthermore, there is also a strong possibility of upper group when activity of II $(p=0.004)$ and IX ( $p=0.012)$ is increased. However, no significant difference in between sex, age and XI was observed.
\end{abstract}

Keywords: Activated partial thromboplastin time, Coagulation factor activity, Reference range, ABO blood type

This is an Open Access article distributed under the terms of the Creative Commons Attribution Non-Commercial License (http://creativecommons.org/licenses/by-nc/4.0) which permits unrestricted non-commercial use, distribution, and reproduction in any medium, provided the original work is properly cited.

Copyright (C) 2015 The Korean Society for Clinical Laboratory Science. All rights reserved.
Corresponding author: Eui-Hoon Kwon Department of Laboratory Medicine, Samsung Medical Center, Seoul 06351, Korea Tel: 82-2-3410-2691

E-mail: euihoon.kwon@samsung.com

Received: September 10, 2015

Revised: October 5, 2015

Accepted: October 7, 2015
서 론

활성화부분트롬보플라스틴시간(activated partial thromboplastin time, aPTT)과 프로트롬빈시간(prothrombin time, PT) 은 혈액응고검사 중 가장 일반적인 검사방법이다.

응고시스템의 비정상적인 밸런스는 출혈 또는 혈전증을 일으키 기도 한다. aPTT는 Langdell 등(1953)에 의해 처음 고안되었으며,
Proctor와 Rappaport (1961)에 의해 발전 되어왔다.

$\mathrm{aPTT}$ 는 내인성경로와 공통경로를 측정하는 대표적인 검사방법 이다. aPTT는 수술 전 출혈에 대한 선별검사나 환자의 직접적인 출 혈을 보기 위한 검사법으로 혈액응고인자 활성에 대한 간접적인 지 표로 활용된다. 또한 헤파린 치료 시 적절한 농도를 조절하기 위한 방법으로 사용되어지고 있다.

$\mathrm{aPTT}$ 는 환자의 혈소판결핍혈장(platelet poor plasma, PPP) 
에 혈소판의 대치성분인 인지질과 내인성경로의 활성제를 넣고수 분간 반응한 후, 칼슘이온 존재 하에 응고가 형성될 때까지의 시간 을 측정하는 방법이다(Shetty 등, 2003). 표면활성제로는 kaolin, ellagic acid, silica, celite 등이 사용되며 XII인자, HMWK (high molecular weight kininogen), prekallikrein 등을 활성화시켜서 내인성경로의 시작을 유도한다.

시약에 포함된 인지질의 성분이 제조사마다 달라서 검사의 민감 도가 다양하기 때문에 검사실마다 CLSI (Clinical and Laboratory Standards Institute) 지침에 근거하여 자체 참고치 범위를 설정하 여야 한다(CLSI, 2008). 검사실에서 검사장비와 시약은 항상 검사 의 정확성을 검증하여야 하며, 상업화 되어 있는 다른 시약들 간에 도 여러 편차가 있을 수 있으므로 검사실의 환경에 맞는 참고치 설 정이 꼭 필요하다(Ross 등, 1980).

본원에서는 정상성인에서의 $\mathrm{aPTT}$ 와 혈액응고인자 활성도 참고 치를 Mean $\pm 2 \mathrm{SD}$ 나 95 백분위수를 이용하여 설정하였다(Table 1) (Jang 등, 2010). 일부 혈액응고인자의 활성도는 성별, 연령 및 $\mathrm{ABO}$ 혈액형 등에 따라 다소 차이를 보이는 것으로 보고되어 있다 (Gill 등, 1987; Souto 등, 2000; Favaloro 등, 2005).

혈액응고검사 중 선별검사로 가장 광범위하게 실시되고 있는 $\mathrm{aPTT}$ 측정에 있어서 한국인의 정상성인에서 경계치의 $\mathrm{aPTT}$ 를 이 용한 혈액응고인자 활성도 평가가 매우 부족한 실정이다. 이에 이 들 경계치의 $\mathrm{aPTT}$ 결과치에 따른 혈액응고인자들의 활성도가 차 이를 보이는지 평가하기 위해 $\mathrm{aPTT}$ 참고치의 하한 측(1 10\%)과 상한 측(91 100\%)에 해당되는 검체를 이용하여 혈액응고인자 II, V, VIII, IX, X, XI, XII 활성도를 분석하여 혈액응고인자들의 유형 분포를 연구하고자 하였다. 그리고 각각 혈액응고인자의 활성도가 성별, 연령 및 $\mathrm{ABO}$ 혈액형 등에서 통계학적으로 유의한 차이를 보 이는지 관찰하고자 하였다.

Table 1. Reference value of normal adults*

\begin{tabular}{|c|c|c|}
\hline Item & Reference value & Units \\
\hline $\mathrm{aPTT}^{\dagger}$ & $29.1 \sim 41.9$ & $\mathrm{sec}$ \\
\hline Factor $\|^{\ddagger}(\mathrm{N}=136)$ & $77 \sim 121$ (99) & $\%$ \\
\hline Factor $\mathrm{V}^{\dagger}(\mathrm{N}=136)$ & $81 \sim 160(113)^{\S}$ & $\%$ \\
\hline Factor $\mathrm{VIII}^{\dagger}(\mathrm{N}=371)$ & $\begin{array}{l}\text { O type } 55 \sim 150(93)^{\S} \\
\text { Non-O type } 77 \sim 205(130)^{\S}\end{array}$ & $\%$ \\
\hline Factor $\mathrm{IX}^{\dagger}(\mathrm{N}=137)$ & $67 \sim 154(97)^{\S}$ & $\%$ \\
\hline Factor $X^{\ddagger}(N=137)$ & $69 \sim 126(98)^{\|}$ & $\%$ \\
\hline Factor $\mathrm{XI}^{\dagger}(\mathrm{N}=137)$ & $59 \sim 138(99)^{\|}$ & $\%$ \\
\hline Factor $\mathrm{XII}^{+}(\mathrm{N}=137)$ & $48 \sim 177(80)^{\S}$ & $\%$ \\
\hline
\end{tabular}

Abbreviation: $\mathrm{N}$, number of individuals tested; aPTT, activated partial thromboplastin time.

*Samsung Medical Center, ${ }^{\dagger}$ Nonnormal distribution, ${ }^{\dagger}$ Normal distribution, "Median, "Mean.

\section{재료 및 방법}

\section{1. 연구대상}

삼성서울병원에서 건강검진을 의뢰한 환자 중에서 CLSI (Clinical and Laboratory Standards Institute) 지침에 근거하여 임상학적, 진단검사의학적으로 정상인 검체만을 대상으로 실험하였다. 본 연 구의 임상학적 제외기준은 출혈과 혈전증과 같은 응고 증상의 임상 적 내역, 간경화증과 악성종양 같은 응고 시스템에 영향을 끼칠 수 있는 질병과 과도한 알코올 중독자, 그리고 경구 피임약 복용 또는 호르몬 치료를 받은 자이다. 진단검사의학적 제외기준은 PT, $\mathrm{aPTT}$ 연장과 비정상적인 간기능 검사 protein, albumin, asparate transaminase, alanine transaminase, gamma-glutamyl transferase), 염증표식자의 증가가 있는 자이다. C-반응성단백질(C-reactive protein, CRP)과 절대호중구수 (absolute neutrophil count, ANC) 는 염증상태를 반영하는 지표검사로 활용 하였다.

aPTT 검사결과 중 29.1 30.9 sec를 하한 측, $38.0 \sim 41.9 \mathrm{sec}$ 를 상한 측으로 정의하여 각각의 혈액응고인자인 II, V, VIII, IX, X, $\mathrm{XI}, \mathrm{XII}$ 활성도를 분석하였다. 분석에 필요한 환자대상은 하한 측 223 명과 상한 측 214 명으로 구분하여 각각 최소 200 명 이상으로 하였다. 본 연구는 삼성서울병원 기관윤리심의위원회의 심의를 통 과하였다(SMC IRB 2011-04-064).

\section{2. 응고검사방법}

검체 용기로는 구연산나트륨이 항응고제로 첨가된 용기 $(\mathrm{BD}$ Vacutainer, Becton Dickinson, Franklin Lakes, NJ, USA)를 사용 하였으며, 용기에는 $0.109 \mathrm{~mol} / \mathrm{L}$ (3.2\%) 구연산나트륨이 $0.3 \mathrm{~mL}$ 들어있고 혈액 $2.7 \mathrm{~mL}$ 를 채취하여 구연산나트륨과 혈액의 비가 1:9가 되도록 제조되어있다. 구연산나트륨은 혈액응고검사에 많 이 이용되고 있는데 그 이유를 보면 구연산나트륨은 다른 항응고제 에 비해 혈장 내 칼슘이온과 신속히 결합하고, 불안정 응고인자인 V번과 VIII번 응고인자를 좀 더 안정하게 유지시키기 때문이다.

본 실험에서는 채혈 후 4 시간 이내의 신선한 검체만 연구대상에 포함 하였으며, 실온에서 $2,330 \mathrm{G}$ 속도로 10 분간 원심분리 하여 혈 장을 분리 검사 하였다. 검사 후 혈장은 소분하여 $-70^{\circ} \mathrm{C}$ 에 보관하 였다.

aPTT 측정은 PTT Automate 시약(Diagnostica Stago SAS, Asnieres, France)으로 검사장비는 STA-R evolution 자동응고분 석기(Diagnostica Stago SAS, Asnieres, France)를 이용하였다. 혈액응고인자 검사에 사용된 시약은 면역흡착에 의해 선택적으로 응고인자 II, V, VIII, IX, X, XI, XII를 제거한 건조 혈장인 STA-deficient II, V, VIII, IX, X, XI, XII (Diagnostica Stago SAS, 
France)이었으며 분석기종은 STA-R evolution 자동응고분석기 (Diagnostica Stago SAS)을 이용하였다. 혈액응고인자 VIII, IX, XI, XII는 STA-CK prest (Diagnostica Stago SAS, Asnieres, France)를 사용하였고, 혈액응고인자 II, V, X은 STA Neoplastin CI Plus (Diagnostica Stago, Asnieres, France)를 사용하여 측정 하였다. aPTT는 내인성경로와 공통경로를 측정하는 검사방법이 기 때문에 외인성경로를 측정하는 VII인자 활성도 분석은 배제하 였다.

혈액응고인자 활성도 검사는 응고법을 이용하여 검사하였다. 환 자의 혈장을 최소 $500 \mu \mathrm{L}$ 씩 분석기에 넣어 혈액응고인자 각각의 활 성도를 측정하였으며, 활성도는 표준화된 정상혈장의 활성도를 기 준으로 하여 $\log -\log$ 그래프를 이용해서 퍼센트 $(\%)$ 로 표시하였다. Coag Control (Diagnostica Stago, Asnieres, France) 정상 및 비 정상 정도관리물질로 검사 시 마다 환자 검체와 함께 정도관리를 시행하였다.

\section{3. 자료분석}

통계분석은 PASW version 17.0 (SPSS Inc., Chicago, IL, USA) 을 이용하였다. 두 군간 연속형 변수의 비교는 정규성 여부에 따라 T-test 또는 Mann-Whitney test로 분석하였으며, 정규성 여부는 Shapiro-Wilk test로 검정하였다.

상관분석도 정규성 여부에 따라 피어슨 상관계수 또는 스피어만 상관계수로 분석하였으며 카이제곱, 다중로지스틱회귀분석을 시 행하였다. $p$ 값이 0.05 미만인 경우 통계학적으로 유의하다고 판정 하였다.

\section{결 과}

\section{1. 연구대상 표본 및 그룹간 변수에 따른 카이제곱검정}

경계치 aPTT 연구대상은 하한 측 223 명, 상한 측 214 명 이었다. 하한 측에서 남자는 117명(52.5\%), 여자는 106명(47.5\%)이었으 며, 상한 측에서 남자는 93명(43.5\%), 여자는 121명(56.5\%)이었 다. 각 그룹별로 연령은 60 세 미만과 이상으로 구분하였다. 하한 측 에서 60 세 미만 160 명 $(71.7 \%), 60$ 세 이상 63 명(28.3\%) 이었으며, 상한 측에서 60 세 미만 177명(82.7\%), 60세 이상 37명(17.3\%)이 었다.

$\mathrm{ABO}$ 혈액형은 $\mathrm{A}$ 형, $\mathrm{B}$ 형, $\mathrm{AB}$ 형, $\mathrm{O}$ 형으로 분류하여 분석하였다. $\mathrm{ABO}$ 혈액형 분류에 의한 결과를 보면 하한 측에서는 $\mathrm{A}$ 형 80 명 (36.2\%), B형 83명(37.6\%), AB형 32명(14.5\%), O형 26명(11.7\%) 의 분포를 보였으며, 상한 측에서는 A형 56명(27.1\%), B형 50명 (24.2\%), AB형 20명(9.6\%), O형 81명(39.1\%)의 분포를 보였다. 하
한 측에서는 $\mathrm{O}$ 형 혈액형이 가장 낮은 빈도를 보였으며, 상한 측에 서는 $\mathrm{O}$ 형 혈액형이 가장 높은 빈도를 보였다. 그리고 $\mathrm{O}$ 형 혈액형과 $\mathrm{O}$ 형 혈액형이 아닌 나머지 A형, B형, AB형을 non-O형(이하, non-O형)이라 분류하였다. O형과 non-O형의 비율은 하한 측에 서 O형 26명(11.7\%), non-O형 195명(88.3\%)이었으며, 상한 측 은 O형 81명(39.1\%), non-O형 126명(60.9\%)이었다. 연구당시에 $\mathrm{ABO}$ 혈액형이 의뢰되지 않아 혈액형을 확인할 수 없는 경우가 하 한 측에서 2예, 상한 측에서 7예 관찰되어 결측치로 간주하였다. 그 룹간 성별과 연령, 혈액형에 따른 두 변수가 서로 독립적인 관계임 을 확인하기 위하여 카이제곱검정을 실시하였다.

그룹간 성별에 따른 카이제곱 검정결과 성별과는 유의한 차이는 없었다 $(p=0.0595)$. 그러나 60 세 미만과 이상의 연령에 따른 하한 측과 상한 측간의 비율은 유의한 차이가 있었다 $(p=0.0064)$. 하한 측은 28 세부터 89 세까지 연령분포를 보였으며, 상한 측은 18 세부 터 86세까지의 연령분포를 보였다. $\mathrm{ABO}$ 혈액형을 분석한 결과 하 한 측과 상한 측간에는 통계적으로 유의한 차이가 있어 $(p<0.0001)$ 그룹간 $\mathrm{ABO}$ 혈액형의 분포가 다르게 존재한다는 것을 증명하였 다. 또한 $\mathrm{ABO}$ 혈액형에서 하한 측과 상한 측간의 O형과 non-O형 에서도 카이제곱 검정결과 그룹간 $\mathrm{O}$ 형의 비율이 차이가 있음을 확 인하였다 $(p<0.0001)$ (Table 2).

\section{2. 그룹간 평균을 비교하여 유의한 차이가 있는 변수들}

연령과 aPTT, C-반응성단백질, 절대호중구수 및 혈액응고인자 들의 활성도에 따른 하한 측과 상한 측간에 차이가 있는지 알아보 고자 정규성 여부에 따라 II와 V는 T-test를 실행하였고, 나머지는

Table 2. Demographics of the control individulas with lower marginal (LM) and upper marginal (UM) aPTT

\begin{tabular}{lccc}
\hline & $\begin{array}{c}\text { Group LM } \\
(\mathrm{N}=223)\end{array}$ & $\begin{array}{c}\text { Group UM } \\
(\mathrm{N}=214)\end{array}$ & $p$-value \\
\hline Gender & & & 0.0595 \\
$\quad$ Male & 117 & 93 & \\
Female & 106 & 121 & \\
Age & & & 0.0064 \\
Less than 60 & 160 & 177 & \\
More than 60 & 63 & 37 & \\
ABO group & & & $<0.0001$ \\
A type & 80 & 56 & \\
B type & 83 & 50 & \\
AB type & 32 & 20 & \\
O type & 26 & 81 & \\
Missing value & 2 & 7 & $<0.0001$ \\
Ond Non-O group & & & \\
O type & 26 & 81 & \\
Non-O type & 195 & 126 & \\
\hline
\end{tabular}

Abbreviation: $\mathrm{N}$, number of individuals tested. 
Mann-Whitney test를 시행하였다.

$\mathrm{II}$ 는 $p=0.0062, \mathrm{~V}$ 는 $p<0.0001$ 을 보여 두 그룹 간의 유의한 차 이를 확인 하였다. II와 V를 제외한 나머지 그룹간 Mann-Whitney test 결과에서 연령, previous aPTT, aPTT, VIII, IX, X, XI, XII는 모두 $p<0.0001$ 을 보여 두 그룹 간의 유의한 차이를 증명하였다.

염증표식자로 활용한 $\mathrm{C}$-반응성단백질 $(p=0.4516)$ 과 절대호중 구수 $(p=0.1195)$ 는 두 집단 간의 유의한 차이는 없었다(Table 3).

\section{3. 그룹간 수준이 동일할 때 각 그룹의 변수에 미치는 영향}

하한 측과 상한 측간에 포함된 다른 변수들의 수준이 동일할 때, 다중로지스틱회귀분석 결과 성별, 연령, XI를 제외한 나머지 II $(p=0.004), \mathrm{V}(p=0.001)$, VIII $(p<0.001)$, IX ( $p=0.012), \mathrm{X}(p$ $<0.001), \mathrm{XII}(p<0.001)$ 에서는 하한 측과 상한 측간에 유의한 차 이가 있었다.

종속변수 코딩은 하한 측을 1 로, 상한 측을 0 으로 코딩하였으며, 범주형 변수 코딩은 성별에서 여성을 1 로, 남성을 0 으로, 연령에서
는 60 세 미만을 1 로, 60 세 이상을 0 으로 코딩하였다. 회귀계수가 양(+)의관계인 V, VIII, X, XII의 활성도가 증가하면 하한 측일 가능 성이 높고, 반대로 회귀계수가 음(-)의 관계인 II, IX의 활성도가 증가하면 상한 측일 가능성이 높다.

Walds 통계값을 큰 수부터 정렬하면 XII, VIII, X, V, II, IX의 순 으로 나열할 수 있으며 이 값이 클수록 설명력이 크다고 할 수 있다. Nagelkerke R 제곱값은 0.829로서 다중로지스틱회귀분석 결과 $82.9 \%$ 의 설명력을 나타내고 있다(Table 4).

모든 연구실험 대상에서 C-반응성단백질 $0.3 \mathrm{mg} / \mathrm{dL}$ 이하와 절 대호중구수 수치가 $7.5 \times 10^{3} / \mu \mathrm{L}$ 미만임을 확인 하였으며, 이는 염 증상태를 배제하는 결과로 사용하였다.

\section{고 찰}

$\mathrm{aPTT}$ 검사는 헤파린 투여 약물의 모니터링, 수술 전 출혈에 대한 선별검사, 응고기전의 혈액응고인자 결핍여부를 확인하기 위해 많

Table 3. Factor activities of the control individulas with lower marginal (LM) and upper marginal (UM) aPTT

\begin{tabular}{|c|c|c|c|}
\hline & Group LM (N=223) & Group UM $(N=214)$ & \\
\hline & mean $\pm 2 S D$ & mean $\pm 2 S D$ & Patuc \\
\hline Age* & $54 \pm 10$ & $49 \pm 12$ & $<0.0001$ \\
\hline aPTT $(\mathrm{sec})^{\star}$ & $30.1 \pm 0.5$ & $39.4 \pm 1.0$ & $<0.0001$ \\
\hline CRP $(\mathrm{mg} / \mathrm{dL})^{\star}$ & $0.04 \pm 0.14 \quad(\mathrm{~N}=222)$ & $0.04 \pm 0.43(\mathrm{~N}=212)$ & 0.4516 \\
\hline ANC $\left(\times 10^{3} / \mu \mathrm{L}\right)^{*}$ & $3.02 \pm 1.29$ & $2.84 \pm 1.36$ & 0.1195 \\
\hline Factor $\|(\%)^{\dagger}$ & $103 \pm 9$ & $100 \pm 10$ & 0.0062 \\
\hline Factor $\mathrm{V}(\%)^{\dagger}$ & $128 \pm 19$ & $107 \pm 19$ & $<0.0001$ \\
\hline Factor VIII (\%)* & $170 \pm 51$ & $118 \pm 37$ & $<0.0001$ \\
\hline Factor IX (\%)* & $126 \pm 22$ & $105 \pm 23$ & $<0.0001$ \\
\hline Factor X (\%)* & $108 \pm 15$ & $97 \pm 15$ & $<0.0001$ \\
\hline Factor XI (\%)* & $123 \pm 24$ & $97 \pm 27$ & $<0.0001$ \\
\hline Factor XII (\%)* & $109 \pm 25$ & $68 \pm 17$ & $<0.0001$ \\
\hline
\end{tabular}

Abbreviation: aPTT, activated partial thromboplastin time; N, number of individuals tested; CRP, C-reactive protein; ANC, absolute neutrophil count.

${ }^{\star}$ Mann-Whitney test, ${ }^{\dagger}$ T-test.

Table 4. Multiple logistic regression analysis for coagulation factor assay

\begin{tabular}{lrrrrrrr} 
& & & & & & & \multicolumn{2}{c}{$95 \%$ Cl for Exp (B) } \\
\cline { 6 - 8 } & & S.E. & Walds & p-value & Exp (B) & Lower & Upper \\
\hline Age (<60) & -0.694 & 0.484 & 2.057 & 0.151 & 0.499 & 0.193 & 1.290 \\
Gender (Female) & 0.129 & 0.425 & 0.092 & 0.762 & 1.138 & 0.495 & 2.614 \\
Factor II & -0.086 & 0.030 & 8.180 & 0.004 & 0.918 & 0.865 & 0.973 \\
Factor V & 0.037 & 0.012 & 10.413 & 0.001 & 1.038 & 1.015 & 1.061 \\
Factor VIII & 0.044 & 0.007 & 35.215 & 0.000 & 1.045 & 1.030 & 1.060 \\
Factor IX & -0.036 & 0.014 & 6.380 & 0.012 & 0.965 & 0.939 & 0.992 \\
Factor X & 0.080 & 0.021 & 13.908 & 0.000 & 1.083 & 1.039 & 1.129 \\
Factor XI & 0.013 & 0.007 & 3.261 & 0.071 & 1.013 & 0.999 & 1.028 \\
Factor XII & 0.100 & 0.012 & 69.234 & 0.000 & 1.105 & 1.079 & 1.131 \\
\hline
\end{tabular}

Abbreviation: B, coefficient of regression; S.E, standard error; Exp (B), odds ratio; $\mathrm{Cl}$, confidence interval. Nagelkerke $R^{2}: 0.829$. 
이 활용되어지고 있는 검사방법이다(Kitchen 등, 1996; Gausman 과 Malar, 2011; Koo, 2011). aPTT가 연장되는 경우는 헤파린 투 여, direct thrombin inhibitor 존재, Lupus anticoagulant가 존재 하는 경우 그리고, 혈액응고인자의 결핍이 있는 경우이다. 이와는 반대로 $\mathrm{aPTT}$ 가 단축되는 경우는 혈전증인 경우이다.

본 연구는 CLSI 기준에 따라 각 그룹별로 200명 이상의 충분한 실험군을 확보했으며 $\mathrm{aPTT}$ 정상범위의 경계치에서 하한 측과 상 한 측의 혈액응고인자 활성도를 실험한 연구이다. 혈액응 고인자 활성도는 선천적 또는 후천적으로 발생하는 다양한 응고질환의 진 단과 임상적 증상에 중요한 단서를 제공한다.

연령이 증가할수록 $\mathrm{V}, \mathrm{VIII}, \mathrm{IX}, \mathrm{XI}, \mathrm{XII}$ 의 활성도가 증가하고 (Sukhu 등, 2003; Favaloro 등, 2005; Mari 등, 2008), 여성이 남성 보다 II, VII, VIII, IX, X, XI, XII의 활성도가 증가한다는 보고가 있 다(Folsom 등, 1992; Lowe 등, 1997; Favaloro 등, 2005). Jang 등 (2010)에 의하면 혈액응고인자 활성도 참고치 설정시 VIII과 XI의 활성도가 60 세 이상의 연령에서 60 세 미만인 연령보다 높다고 보 고 하였는데, 이번 연구에서 VIII과 IX는 그룹간에 상관없이 60세 이상의 연령에서 높게 관찰 되었다. 이로 미루어 보아 VIII인자는 연령이 증가할수록 혈액응고인자 활성도도 증가하는 것이라 생각 되어진다. 또한 하한 측중에 VIII의 혈액응고인자 활성도가 $300 \%$ 이상을 보인 5 예가 관찰되었다. 연구 중간에 검사결과의 일관성과 검체보관에 대한 신뢰를 확인하기 위해서 $-70^{\circ} \mathrm{C}$ 에 보관중인 혈장 을 $37^{\circ} \mathrm{C}$ 에서 5 분간 해동한 후 전날 혈액응고인자 활성도 검사결과 와 다음날 혈액응고인자 활성도 검사결과를 검증하는 회복능시험 을 10예 시행하였는데 실험결과 II, V, X은 변이계수값이 모두 $\pm 10 \%$ 이내였지만 VIII 4 예, IX 1예, XI 1예, XII 2예 에서는 변이계 수값이 $\pm 10 \%$ 를 벗어났다. 이러한 결과는 내인계 응고기전의 혈액 응고인자들의 짧은 반감기에 기인한 것으로 생각된다.

$\mathrm{ABO}$ 혈액형의 표현형과 VIII인자 사이의 관계는 Preston과 $\operatorname{Barr}$ (1964)에 의해 처음 보고 되었고, O형 그룹이 non-O형 그룹 보다VWF (von Willebrand factor) 항원의 레벨이 더 낮다고 보고 되었다. O형은 VWF나 VIII인자의 농도가 낮아 혈액응고 측면에서 불리하다는 보고들이 많다(Jeremic 등, 1976; McLellan 등, 1988; Fourel 등, 1993; Kim 등, 1995; Moellera 등, 2001). McCallum 등(1983)은 O형에서 A, B, AB형 보다 VIII인자의 활성도가 낮다고 보고 하였고, Orstavik 등(1985)은 VIII인자의 운반단백인 VWF와 $\mathrm{ABO}$ 혈액형 사이의 연관성을 밝혀냈다. VIII인자의 기능을 안정화 시키는 VWF의 농도가 상대적으로 낮은 O형에서 VIII인자의 활성 도가 감소되어 있는 것은 당연하다고 할 수 있다. Gill 등(1987)은 non-O형이 O형에 비하여 VIII인자와 VWF 복합체의 농도가 약 $25 \%$ 더 높다고 보고하였다.
본 연구에서 하한 측에서는 O형 혈액형이 가장 낮은 빈도(26명, $11.7 \%)$ 를 보였으며, 상한 측에서는 $\mathrm{O}$ 형 혈액형이 가장 높은 빈도 (81명, 39.1\%)를 보였다. O형과 non-O형에서 그룹간의 차이를 살 펴보면 VIII인자는 양쪽 그룹에서 모두 유의하게 차이를 보였으며, 이러한 결과는 VIII인자의 활성도를 O형과 non-O형으로 구분해 야 한다는 필요성을 명확하게 보여주는 것이라 할 수 있다. Jang 등 (2010)의 연구에 의하면 VWF 항원과 VIII 인자 사이의 강한 상관 성이 있음을 보고하였다. O형 혈액형의 VWF는 ADAMTS13 (a disintegrin and metalloproteinase with a thrombospondin type 1 motif, member 13) 단백분해 영향에 더 민감하게 반응하는 것으로 알려져 있다(O'Donnell 등, 2005).

결론적으로 본 연구에서 $\mathrm{aPTT}$ 경계치에 속한 혈액응고인자 활 성도를 시행한 연구 결과, 60세 미만과 이상으로 구분한 연령군에 서 V, VIII, IX, XII의 혈액응고인자 활성도가 유의한 차이를 보였다 는 것은 연령에 따른 혈액응고인자 활성도가 다르다는 근거를 제시 할 수 있을 것이다. 또한, $\mathrm{ABO}$ 혈액형 분류에 의한 $\mathrm{O}$ 형과 non-O형 으로 구분한 그룹간의 차이에서 VIII의 혈액응고인자 활성도는 양 쪽 그룹에서 모두 유의한 차이를 보였다. 이러한 점에서 VIII의 혈 액응고인자 활성도는 O형 혈액형과 non-O형 혈액형으로 구분한 참고치 설정에 꼭 필요하다고 할 수 있을 것이다.

다중로지스틱회귀분석 결과에서 V, VIII, X, XII의 활성도가 증 가하면 하한 측일 가능성이 높고, 반대로 II, IX의 활성도가 증가하 면 상한 측일 가능성이 높다. 또한 유의한 차이가 있는 혈액응고인 자들의 Walds 통계값을 큰 수부터 유추해보면 경계치의 aPTT 검 사결과에 가장 크게 영향을 미치는 혈액응고인자는 XII, VIII, X, V, II, IX이었다.

VIII과 VWF의 높은 상관성을 고려한다면 이번 연구에서 VWF 검사를 같이 병행했더라면 좀 더 객관적인 결과를 제시할 수 있으 리라 판단된다. 과거 $\mathrm{aPTT}$ 검사와 최근 $\mathrm{aPTT}$ 검사결과가 참고치 의 경계치에 근접한 패턴을 계속 유지한다면 유전자 검사 및 가족 력 검사를 시행하여 계속적인 추적관찰이 필요하다고 생각된다.

\section{요 약}

$\mathrm{aPTT}$ 참고치의 정상범위 내에서 하한측 10\% (29.1 30.9 sec) 와 상한 측 10\% (38.0 41.9 sec)에 포함된 정상성인의 혈액응고 인자 활성도를 분석하여 하한 측과 상한 측간에 혈액응고인자의 종 류와각각의 활성도가 성별, 연령 및 $\mathrm{ABO}$ 혈액형 등에 통계학적으 로 유의한 차이를 보이는지 알아보고자 하였다. 성별에 따른 혈액 응고인자들의 활성도 차이를 분석한 결과 하한 측에서 $\operatorname{IX~}(p=0.0088)$ 만 남성이 여성보다 높았으며, 상한 측에서 IX $(p<0.0001)$ 와 X 
( $p=0.0013)$ 은 남성이 여성보다 높았다. 연령군간 혈액응고인자들 의 활성도 차이 검정은 하한측에서 $\operatorname{VIII}(p<0.0001), \operatorname{IX}(p=0.0050)$ 는 60세 이상이 60세 미만보다 높았으며, XII ( $p=0.0285)$ 는 60세 이상보다 60세 미만이 높았다. 상한 측에서 $\mathrm{V}(p=0.0219)$, VIII ( $p=0.0005), \operatorname{IX}(p=0.0014)$ 는 60세 이상이 60세 미만보다 높았다. O형과 non-O형의 혈액형 구분에 의한 혈액응고인자들의 활성도 차이는 VIII $(p<0.001)$ 은 양쪽 그룹에서 non-O형이 O형보다 높 았으며, XII ( $p=0.016)$ 는 상한 측에서 non-O형이 O형보다 낮았다.

\section{Acknowledgements: None \\ Funding: None \\ Conflict of interest: None}

\section{References}

1. CLSI. Defining, establishing and verifying reference intervals in the clinical laboratory; approved guideline, 3rd edition. CLSI document CA28-A3. 2008. Clinical and Laboratory Standards Institute, Wayne, Pennsylbania.

2. Favaloro EJ, Soltani S, McDonald J, Grezchnik E, Easton L. Cross-laboratory audit of normal reference ranges and assessment of $\mathrm{ABO}$ blood group, gender and age on detected levels of plasma coagulation factors. Blood Coagul Fibrinolysis. 2005, 16:597-605.

3. Folsom AR, Conlan MG, Davis CE, Wu KK. Relations between hemostasis variables and cardiovascular risk factors in middle-aged adults. Atherosclerosis Risk in Communities (ARIC) Study Investigators. Ann Epidemiol. 1992,2:481-94.

4. Fourel V, Gabastou JM, Desroys du Roure F, Ehrhardt N, Robert A. Influence of age, sex and ABO blood group on activated partial thromboplastin time. Haemostasis. 1993,23:321-326.

5. Gausman JN, Malar RA. Unaccuracy of a "spiked curve" for monitoring UFH therapy. Am J Clin Pathol. 2011,135:870-876.

6. Gill JC, Endres-Brooks J, Bauer PJ, Marks WJ, Montgomery RR. The effect of $\mathrm{ABO}$ blood group on the diagnosis of von Willebrand disease. Blood. 1987,69:1691-1695.

7. Jang JH, Seo JY, Bang SH, Park IA, Kim HJ, Kim SH. Establishment of reference intervals for von Willebrand factor antigen and eight coagulation factors in a Korean population following the Clinical and Laboratory Standards Institute guidelines. Blood Coagul Fibrinolysis. 2010,21:251-255.

8. Jeremic M, Weister O, Gedde-Dahl TW. Factor VIII(AHG) levels in 1016 regular blood donors: The effects of age, sex, and ABO blood groups. Scand J Clin Lab Invest. 1976,36:461-466.

9. Kim MJ, Lee AN, Song KS, Kim YJ, Shim AS. Influence of Age, Sex and ABO Blood Group on Activated Partial Thromboplastin Time (APTT). Korean J Hemosat Thromb. 1995,2:155-159.

10. Kitchen S, Jennings I, Woods TAL, Preston FE. Wide variability in the sensitivity of APTT reagents for monitoring of heparin dosage. J Clin Pathol. 1996,49:10-4.
11. Koo BK, Kwon EH, Ryu KH, Yun JW, Kim HJ. Comparison of Two Methods for Heparin Sensitivity; Activated Partial Thromboplastin Time Assay using in vitro Heparin-spiked Sample and Anti-Xa Assay using in vivo Heparin-treated Sample. Korean J Clin Lab Sci. 2011,43:133-137

12. Langdell RD, Wagner RH, Brinkhous KM. Effect of antihemophilic factor on one-stage clotting tests; a presumptive test for hemophilia and a simple one-stage antihemophilic factor assay procedure. J Lab Clin Med. 1953,41:637-647.

13. Lowe GD, Rumley A, Woodward M, Morrison CE, Philippou H, Lane DA, et al. Epidemiology of coagulation factors, inhibitors and activation markers: the Third Glasgow MONICA Survey. I. Illustrative reference ranges by age, sex and hormone use. $\mathrm{BrJ}$ Haematol. 1997,97:775-84.

14. Mari D, Coppola R, Provenzano R. Hemostasis factors and aging. Exp Gerontol. 2008,43:66-73.

15. McCallum CJ, Peake IR, Newcombe RG, Bloom AL. Factor VIII levels and blood group antigens. Thromb Haemost. 1983, 50:757.

16. McLellan DS, Knight SR, Aronstam A. The relationship between coagulation factor VIII and ABO blood group status. Med Lab Sci. 1988,45:131-134.

17. Moellera A, Weippert-Kretschmer M, Prinz H, Kretschmer V. Influence of ABO blood groups on primary hemostasis. Trans ${ }^{-}$ fusion. 2001,41:56-60.

18. O'Donnell JS, McKinnon TA, Crawley JT, Lane DA, Laffan MA. Bombay phenotype is associated with reduced plasma-VWF levels and an increased susceptibility to ADAMTS13 proteolysis. Blood. 2005,106:1988-1991.

19. Orstavik KH, Magnus P, Reisner H, Berg K, Graham JB, Nance W. Factor VIII and Factor in a twin population: Evidence for a major effect of ABO locus on factor VIII level. AmJ Hum Genet. 1985,37:89-101.

20. Preston AE, Barr A. The plasma concentration of factor VIII in the normal population. II. The effects of age, sex and blood group. Br J Haematol. 1964,10:238-245.

21. Proctor RR, Rapaport SI. The partial thromboplastin time with kaolin. A simple screening test for first stage plasma clotting factor deficiencies. Am J Clin Pathol. 1961,36:212-219.

22. Ross JW, Fraser MD, Moore TD. Analytic clinical laboratory precision: state of the art for thirty-one analysis. Am J Clin Pathol. 1980,74:521-530.

23. Shetty S, Ghosh K, Mohanty D. Comparison of four commercially available activated partial thromboplastin time reagents using a semi-automated coagulometer. Blood Coagul Fibrinolysis. 2003,14:493-497.

24. Souto JC, Almasy L, Muniz-Diaz E, Soria JM, Borrell M, Bayen L, et al. Functional effects of the $\mathrm{ABO}$ locus polymorphism on plasma levels of von Willebrand factor, factor VIII, and activated partial thromboplastin time. Arterioscler Thromb Vasc Biol. 2000,20:2024-2028.

25. Sukhu K, Poovalingam V, Mahomed R, Giangrande PL. Ethnic variation in von Willebrand factor levels can influence the diagnosis of von Willebrand disease. Clin Lab Haematol. 2003,25: 247-9. 